\title{
Revista Brasileira de Enfermagem REBEn \\ Formação de formadores: a prática educativa de um programa de pós-graduação em enfermagem
}

\author{
Forming teachers: the educational practice in a graduate nursing program \\ Formando a maestros: la practica educativa en un programa de postgrado en enfermería
}

\section{Cassandra Genoveva Rosales Martins Ponce de Leon}

Enfermeira. Mestre em Enfermagem Fundamental pela Universidade Federal da Paraíba, João Pessoa, $P B$

Endereco para contato QRSW, Qd 03, lote 01, apto.209, Ed Bomtempo, Sudoeste, Brasília, DF. CEP

70.675-300. casandraleon@yahoo.com.br

\section{César Cavalcanti da Silva}

Enfermeiro. Professor Doutor do Departamento de Enfermagem de MédicoCirúrgica e Administração do Centro de Ciências da Saúde da Universidade Federal da Paraíba, João Pessoa, $P B$. profccs@yahoo.com.br

Este artigo é resultado da Dissertação de Mestrado em Enfermagem Fundamental. Ano de conclusão 2006

\section{RESUMO}

Compreender as Práticas Educativas operadas na Pós-Graduação em Enfermagem do Centro de Ciências da Saúde da Universidade Federal da Paraíba - CCS/UFPB e identificar as contradições produzidas, à luz de referenciais pedagógicos emancipatórios e não emancipatórios foram objetivos deste trabalho. Trata-se de um estudo de abordagem qualitativa. Os professores e alunos do Programa de Pós-Graduação em Enfermagem da UFPB foram os sujeitos do estudo. Foi utilizada a entrevista semi-estruturada e a análise dos dados ocorreu através da técnica de análise de discurso. A categoria empírica evidenciada foram: Contradições no Processo de Formação de Formadores e a Influência das Práticas Educativas Emancipatórias e não Emancipatórias. Constatou-se que a Prática Educativa dos docentes encontra-se alicerçada em bases não Emancipatórias, fato ratificado pelo discurso dos discentes.

Descritores: Educação em enfermagem; Educação de pós-graduação em enfermagem; Prática do docente de enfermagem.

\section{ABSTRACT}

This study aimed at understanding the educational practices operated in the Graduate Nursing Program of the Center of Sciences of the Health of the Federal University of Paraiba - UFPB and at identifying the produced contradictions, to the light of emancipatory pedagogic references and also non-emancipatory ones. This is a study of qualitative approach. The teachers and students of the Graduate Nursing Program of UFPB were the subject of the study. The semi-structured interview was used, and the analysis of the data happened through the technique of speech analysis. The evidenced empiric categories were: Contradictions in the Process of Formation of Teachers and Influence of the Educational Emancipatory ando non-Emancipatory Practices. It was verified that the teachers' Educational Practice is found in bases of non-Emancipatory, fact ratified by the speech of the students.

Descriptors: Education, nursing; Education, nursing, graduate; Nursing faculty practice.

\section{RESUMEN}

El objectivo de este estudio fue entiender las prácticas educativas operadas en el Programa Postgrado en Enfermería del Centro de Ciencias de la Salud de la Universidad Federal de Paraíba - UFPB y identificar las contradicciones producidas, a la luz de referencial pedagógicos emancipatorios y no emancipatorio. Es un estudio con abordaje cualitativo. El cuerpo docente y los estudiantes del Programa Postgrado en Enfermería de la UFPB fueron los sujetos del estudio. La entrevista semi-estructurada fue usada, y el análisis de los datos fue a través de la técnica de análisis del discurso. La categoría empírica evidente fueran: Contradicciones en el Proceso de Formación de Maestros y Influencia de las Practicas Educativas Emancipatorias y no Emancipatorias. Se observo que las Prácticas Educativas de los docentes se encuentra alicersada en bases no Emancipatorias, ratificado por el discurso de los estudiantes. Descriptores: Educación en enfermería; Educación de postgrado en enfermería; Practica del docente de enfermería.

Ponce de Leon CGRM, Silva CC. Formação de formadores: a prática educativa de um programa de pósgraduação em enfermagem. Rev Bras Enferm 2006 set-out; 59(5): 636-41.

\section{INTRODUÇÃO}

Este trabalho faz parte de um estudo realizado no Programa de Pós-Graduação em Enfermagem, requisito para conclusão do Mestrado, e a motivação para a realização deste estudo surgiu das diversas discussões com o orientador, que fez despertar, na pesquisadora, o interesse sobre questões inerentes à formação profissional, em nível Stricto Sensu, e suas repercussões na formação de força de trabalho para a Enfermagem, em atenção à necessidade de consolidação do Sistema Único de Saúde -SUS, nessa área. 
Considerando-se os atuais requerimentos das políticas de educação e de saúde, urge a superação das contradições advindas do confronto entre a opção por práticas educativas não emancipatórias e o processo formativo em vigência como meio para o atendimento das políticas de inclusão social, cada vez mais acentuadas, com a redefinição das prioridades de atenção à saúde e a conseqüente necessidade de um novo perfil profissional, longe de ser alcançado pelo paradigma tradicional de formação.

Na atualidade, os processos de ensino para a formação de enfermeiros e, particularmente, para a formação de formadores, passam por um importante momento de transição paradigmática, sendo a grande certeza na questão educacional como um todo a urgência de se redefinir o papel das instituições no âmbito da formação, bem como a atuação dos docentes e discentes, nesses processos ${ }^{(1)}$.

Pinheiros, Rodrigues ${ }^{(2)}$ assinalam que as transformações dos órgãos formadores perpassam a experimentação de novas tendências teóricas e estratégias de ensino nos processos formativos do enfermeiro. Os autores acreditam que as dificuldades de se implementarem transformações na prática profissional surgem ainda nos processos de formação, adiantando que, se o ensino formal de enfermagem tem interesse de graduar profissionais questionadores e reflexivos, é fundamental, se repensar as estratégias de ensino, seus referenciais teóricos, além de fomentar reflexões, discussões e análises do papel dos docentes e discentes nesses processos.

A reflexão sobre as transformações necessárias nas práticas educativas tem importância estratégica nesse momento histórico, devido ao redirecionamento do processo formativo determinado pelas Diretrizes Curriculares Nacionais para os Cursos de Graduação em Enfermagem, materializadas pela Resolução CNE/CES No03/ 2001, que aponta para a formação de enfermeiros providos de competências e habilidades gerais e específicas. O referido diploma legal prevê ainda a necessidade de mudanças nos perfis profissionais dos enfermeiros, de modo que sua formação possa atender às necessidades sociais da saúde, decorrentes da implementação do Sistema Único de Saúde - SUS e de seus princípios norteadores (doutrinários e organizativos)

Especificamente em relação à formação de formadores, o mestrado, é preciso que se forneçam subsídios aos docentes para repensarem e modificarem sua Prática Educativa, considerando a necessidade de formar formadores capazes de produzir sujeitos críticos, reflexivos e questionadores, em resposta às necessidades sociais da Saúde. Portanto, é pertinente promover discussões mais aprofundadas na Universidade, precisamente nos Programas de PósGraduação, acerca da possibilidade de transformação das Práticas Educativas e da implementação de um ensino diferenciado, como orientador dos processos de formação, tendo em vista as necessidades sociais da saúde, no âmbito da formação da força de trabalho.

Nesse sentido, o objeto deste estudo são as Práticas Educativas dos professores vinculados ao Programa de Pós-Graduação em Enfermagem do Centro de Ciências da Saúde da Universidade Federal da Paraíba - CCS/ UFPB, visando à necessidade de se compreender os limites e as possibilidades de um processo de transformação promovido por mudanças na prática educativa.

Questiona-se, então: Que mudanças pedagógicas precisam ocorrer nas Práticas Educativas em uso na Pós-Graduação em Enfermagem do CCS/ UFPB, para permitir que a formação desses formadores avance no sentido de atender às necessidades sociais da saúde, com ênfase no Sistema Único de Saúde - SUS, em articulação com as competências e habilidades recomendadas pelas Diretrizes Curriculares Nacionais do Curso de Graduação em Enfermagem?

\section{OBJETIVOS}

Para responder tal questão, formulamos os seguintes objetivos: Compreender as Práticas Educativas Emancipatórias e não Emancipatórias operadas na Pós-Graduação em Enfermagem do CCS/UFPB e o modo como se refletem na formação de formadores da força de trabalho de Enfermagem; e identificar as contradições produzidas pelas Práticas Educativas praticadas no Programa de Pós-Graduação em Enfermagem do CCS/UFPB, à luz de referenciais pedagógicos Emancipatórios e não Emancipatórios, tendo em vista o processo de formação de formadores.

\section{METODOLOGIA}

Trata-se de um estudo de caráter descritivo e de abordagem qualitativa, que teve como suporte teórico-metodológico a orientação da TIPESC - Teoria da Intervenção Práxica da Enfermagem em Saúde Coletiva ${ }^{(3)}$.

O cenário do estudo foi o Programa de Pós-Graduação em Enfermagem do Centro de Ciências da Saúde da Universidade Federal da Paraíba CCS/UFPB, e os sujeitos foram os docentes e discentes do referido Programa. Participaram quatro docentes e discentes, perfazendo um total de oito participantes.

Após liberação pelo Comitê de Ética do CCS/UFPB, procedeu-se à coleta dos dados, que ocorreu entre os meses de abril a junho de 2005. Utilizou-se a entrevista semi-estruturada, e a análise dos dados decorreu através da análise do discurso, proposto por Fiorin ${ }^{(4)}$. Aentrevista dirigida aos docentes e discentes permitiu apreender o posicionamento desses sujeitos sociais nos processos de ensino e de avaliação utilizados no Programa de Pós-Graduação em Enfermagem do CCS/UFPB.

\section{RESULTADOS}

Para identificar o componente Emancipatório da Prática Educativa dos professores, considerou-se os pontos de identificação e convergências dos trechos discursivos, identificados e separados de acordo com o posicionamento político dos docentes com base no referencial teórico estudado. O resultado dessa manobra evidenciou dois tipos de posicionamento: Professores com Práticas Educativas Emancipatórias e Professores com Práticas Educativas Não Emancipatórias, conforme pode ser observado no quadro 1.

A determinação do posicionamento Emancipatório e Não Emancipatório encontra sustentação nos estudos de Mizukami ${ }^{(5)}$, onde está explícito que, quando o conhecimento é posto em um plano secundário e a Prática Educativa passa a assumir um significado amplo, tal qual é dado à política, o objetivo do professor passa a ser o desenvolvimento da consciência crítica dos alunos, amparada pelo seu sentimento de liberdade, sendo, portanto, Emancipatório.

Nessa tendência ou abordagem, os conhecimentos existentes são importantes, porém não são tidos como verdades inabaláveis e eternas, sendo passivel de sofrer críticas, reflexões e transformações, sendo esta uma concepção, também, sustentada pelos referenciais de Freire ${ }^{(6)}$, Saviani ${ }^{(7-9)}$, Libaneo ${ }^{(10-12)}$ e Diaz-Bordenave e Pereira ${ }^{(13)}$.

Um exemplo de Educação não Emancipatória é observado quando não se permite, ao aluno, questionar, analisar ou refletir sobre os conhecimentos já existentes. Prevalecendo a reprodução dos conhecimentos, sem que seja desenvolvida, nos discentes, uma consciência crítica ou analítica.

Por outro lado, quando a Prática Educativa se encontra subordinada à Instrução, reduz-se à transmissão de conhecimentos, auxiliada por estratégias didáticas, das várias abordagens pedagógicas não emancipatórias, encontrando aí seu maior respaldo.

Assim, o refinamento dos trechos discursivos dos sujeitos deste trabalho, visando ao enxugamento dos temas mais relevantes relacionados com o objeto do estudo, evidenciou várias contradições no fenômeno estudado, dentre as quais a utilização concomitante de práticas educativas emancipatórias e não emancipatórias, pelo mesmo docente, tanto nos processos de ensino quanto nos de avaliação.

Através da visualização da contradição teoria $x$ prática, predominante no cenário investigado, apresentou-se como categoria empírica do estudo 


\begin{tabular}{|c|c|c|c|c|c|}
\hline 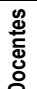 & \multicolumn{2}{|c|}{ Abordagem pedagógica / Posicionamento Político } & 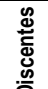 & \multicolumn{2}{|c|}{ Abordagem pedagógica / Posicionamento Político } \\
\hline 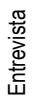 & Para o Ensino & Para a avaliação & 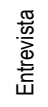 & Para o Ensino & Para a Avaliação \\
\hline 01 & $\begin{array}{l}\text { - Não Emancipatório } \\
\text { - Emancipatório }\end{array}$ & $\begin{array}{l}\text { - Não Emancipatório } \\
\text { - Emancipatório }\end{array}$ & 01 & -Não Emancipatório & - Não Emancipatório \\
\hline 02 & $\begin{array}{l}\text { - Emancipatório } \\
\text { - Não Emancipatório }\end{array}$ & - Emancipatório & 02 & - Não Emancipatório & - Não Emancipatório \\
\hline 03 & - Emancipatório & - Emancipatório & 03 & - Não Emancipatório & - Não Emancipatório \\
\hline 04 & - Não Emancipatório & - Não Emancipatório & 04 & - Não Emancipatório & - Não Emancipatório \\
\hline
\end{tabular}

\section{Quadro 1. Abordagens pedagógicas que amparam a prática educativa (ensino e avaliação) dos docentes, e como são percebidas na visão dos discentes.}

Contradições no processo de formação de formadores: influência das práticas educativas emancipatórias e não emancipatórias e, como categoria interpretativa do fenômeno, Processos de ensino e de avaliação emancipatórios e não emancipatórios,

Nesse sentido, buscou-se em Freire ${ }^{(6)}$, Saviani ${ }^{(7)}$, Libaneo ${ }^{(10)}$ e DiazBordenave e Pereira ${ }^{(13)}$ referenciais para auxiliar na análise dos dados. 0 quadro 2 apresenta uma síntese das Abordagens Emancipatórias.

Ferreira ${ }^{(14)}$ apresenta uma definição de educação e instrução que são pertinentes, tendo a educação como significado amplo, complexo, o de promover o desenvolvimento da capacidade intelectual, moral e física de (alguém) ou de si mesmo; e a instrução sendo definida como transmissão de conhecimento a (alguém), ensinar, ensinar como proceder, adestrar, domesticar, transmitir instruções, informar, esclarecer, entre outras definições.

Desta forma, à luz dos referenciais Emancipatórios e das definições acima apresentadas, revelam-se os discursos dos docentes, em relação ao processo de ensino, salientando que apenas dois docente foram coerentes na sua prática educativa, utilizando, um docente a abordagem emancipatória, e outro a não emancipatória, tanto no processo de ensino quanto na avaliação; enquanto que os demais docentes em determinados momentos utilizam a abordagem emancipatória e não emancipatória, sendo esta uma contradição na prática educativa dos docentes.

O docente D1 apresenta contradição no seu discurso, como pode ser observado nos trechos seguintes:

Então, um exemplo: nós tivemos uma certa dificuldade em compreender o que é..., e para que isso fosse possivel, os alunos fizeram uma espécie de grupo, eles se arrumaram em grupos e tentaram problematizar na situação... (D1).

Utilizamos um trabalho de grupo, uma discussão. (D1).

A avaliação, eu faço desde o começo, primeiro, no primeiro momento da aula, eu quero saber, eu anuncio os objetivos da aula, eu solicito se os alunos têm algum ponto de pauta para incluir e eu vejo o nivel deles em relação àquilo que está sendo proposto para estudar. (D1)

... tirando as suas dúvidas, e ao mesmo tempo, estou avaliando a capacidade do aluno de ir adiante, ir à frente. (D1).

Até este momento poder-se-ia afirmar que o professor se mostra interessado no desenvolvimento intelectual dos alunos, porém no discurso que se segue, observa-se que o importante é a memorização dos conteúdos repassados em sala de aula.

Eu solicito feedback, devolução mesmo de conteúdo, numa abordagem bem tradicional. Então, vai depender muito do aluno, dos alunos, da turma, da dinâmica, de como o Curso está caminhando. (D1).

Em relação ao professor D2, observa-se presença da abordagem emancipatória e não emancipatória no processo de ensino e na avaliação, a utilização de abordagem emancipatória.

Bom, uma das situações que eu considero extremamente importante que facilita o processo ensino-aprendizagem do aluno, na minha opinião, isso ocorre muito mais fora da sala de aula do que dentro. (D2)

A gente não só ministrou uma aula teórica, mas elas vivenciaram na prática. Uma nova abordagem da saúde ..., uma nova tecnologia do cuidado, ela sendo executada. Porque é dessa forma que o aluno compreende melhor.... primeiro eles vivenciam, depois têm o conhecimento teórico. Então foi assim que a gente fez. Primeiro fomos para a comunidade, experienciaram e na aula seguinte, eles foram conhecer toda a construção teórica do Modelo... (D2).

Bom, a gente não fez uma avaliação formal, de prova ou relatório nessa experiência. Ela foi muito mais verbal, do que mesmo mensurada. Foi uma discussão, uma reflexão. E para a gente, isso é muito mais simples, porque a turma era constituída apenas seis alunos, então a gente fez um momento de reflexão, de vivência, e ai foram formuladas as expressões, as falas, os sentimentos deles ... (D2).

O sujeito D3 foi o professor coerente na prática educativa utilizando a abordagem Emancipatória, como pode ser evidenciado nos discursos que se seguem:

Eu considero que a aula mais proveitosa, até hoje, realizada por mim com os alunos do Mestrado foi quando vivenciamos a prática no, e onde a gente pode, além de vivenciar a prática, é uma reflexão de vida. (D3).

A teoria, eu acredito que tem que ser toda na base da problematização. A teoria tem que ser trazida de situações vivenciadas no cotidiano, para a teoria. Não trazer nada pronto, tá certo? Mas ali, vivenciando aquela prática, é como você pode realmente desenvolver um cuidar específico para cada problema. Se eu levo somente teoria, então eu estou muito distanciada da nossa prática, porque as práticas são diferenciadas, não é? (D3).

..., além de trazer uma reflexão, trouxe até um melhor desempenho, ou seja, a perspectiva de um novo cuidar, numa visão crítica para os 
alunos da Enfermagem. Então eu acho que foi uma reflexão muito grande, assim, os alunos depois realizaram um trabalho também na temática. (D3).

A principal avaliação, parte no sentido de quê... que a pessoa absorva aquela realidade e possa fazer uma análise crítica da situação. A sua participação enquanto ser humano, enquanto profissional, enquanto Enfermeiro, enquanto Pós-graduando, que visão tem aquela situação e também as possiveis soluções para o problema? Porque, também, se a gente só vê o problema e não consegue perceber que existe uma solução, ou pelo menos uma luz no fim do túnel, então a gente não aprendeu. (D3).

Já o docente D4, utilizando a abordagem não emancipatória, mostrouse coerente na sua prática educativa, utilizando a abordagem não emancipatória.

Agora, a minha maneira de dar aula é expor o conteúdo e escutar a resposta dos alunos. Ou seja, a aula só faz sentido se os alunos participarem, né? Tá conversando com eles e eles saibam responder e colocando suas dúvidas, vivências deles, e aí tentar construir conjunto... na Pós, eles são adultos e têm uma discussão... (D4).

Então, a minha avaliação é pensar como ele entrou e quando ele saiu, e qual foi o ganho que ele teve durante o curso. (D4).

$\mathrm{Na}$ Graduação, esse esquema, fazer provas, funciona legal. Na Pós, é uma perda de tempo, na Pós, a avaliação é aquilo que consigo ver, ... (D4).

... de uma maneira geral, na Pós, a avaliação é dessa interação quotidiana, e eu, pelos meus critérios. (D4).

... eu acho que o trabalho pode dar suporte para te defender numa opinião tua. Tipo assim: Você sabe que aquele aluno não é bom, que ele vai reclamar, que você vai dar nota baixa, então se eu der um trabalho, eu sei que ele vai fazer um trabalho ruim. Então, esse trabalho vai me garantir que a nota que eu dei, ele não vai reclamar. No máximo serve para isso. (D4).

Os discursos dos discentes revelou que os docentes do Programa de
Pós-Graduação em Enfermagem têm a sua Prática Educativa alicerçada em abordagens não emancipatórias, como pode ser visto nos discursos seguintes:

... Era uma aula totalmente expositiva, uma aula da profa $X$. Aquela aula é uma aula típica, assim, que você chega para assistir. Você chega, senta ali e ela vai passar os conteúdos. (A1).

... eu acho que a forma didática de ela abordar, assim, aquelas coisas ilustrativas, começava tudo com aquela parte de... como é que se chamava? Visual. Que ela colocava mensagens, e essas, mesmo que a gente estivesse com muitos problemas e viesse a se sentir de qualquer forma. ... nós parávamos e refletiamos e depois nós conseguíamos cair numa real e, a partir daí, ela começava o objetivo da aula dela. (A2).

Então, a disciplina transcorreu assim: $A$ gente recebeu conteúdos para a nossa vida prática, mas, também, para que melhorasse 0 nosso projeto em si, o que eu acho que é primordial. (A3).

... e no decorrer que a gente vai tendo aula com os professores, que têm conhecimentos extremos, à vista da gente, a gente fica impressionada com determinadas aulas, com a paciência dos professores em querer ajudar, então, isso vai nos ajudando a crescer. (A3)

Eu acho que ninguém chega numa Pós-Graduação querendo brincar. Então eu acho que as cobranças excessivas, por parte de alguns professores, são desnecessárias. Mas a minha vivência negativa foi em relação a isso, eu me frustrei em alguns momentos, porque eu não esperava isso numa Pós-Graduação. (A4).

Eu achei isso uma cobrança excessiva. Me trouxe, não só para mim, para colegas meus, uma situação de estresse. Eu cheguei em casa realmente a chorar, a querer desistir (A4).

No tocante à avaliação utilizada pelos docentes, na percepção e vivência dos discentes, observou-se coerência na escolha da abordagem, ratificando a escolha dos docentes por uma educação subordinada à Instrução, ou seja, a abordagem não emancipatória.

Então, a avaliação ... todo o conteúdo era passado, então a avaliação

\begin{tabular}{|c|c|c|c|c|}
\hline \multirow{2}{*}{ Auteres: } & \multirow{2}{*}{ Azordagem Emanaisatïria } & \multicolumn{2}{|c|}{ Pritioa Educativa } & \multirow{2}{*}{ Carasteristioas prinoipais } \\
\hline & & Eraho & Avalecás & \\
\hline $\operatorname{sen}(a n)$ & Tesia Helstorito-Critica & 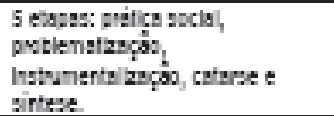 & Rlas acresents infonragkes. & 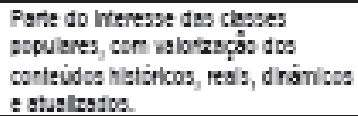 \\
\hline Freinef & Rzordajen Proternatzstors & 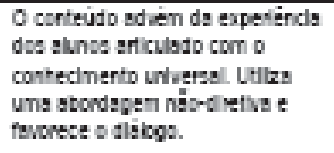 & Auto-sualsçä & 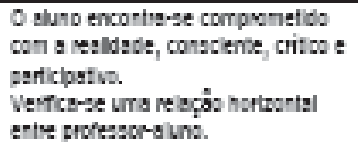 \\
\hline Lbened/9 & $\begin{array}{l}\text { Teoria Cnitico Bocial tos } \\
\text { Conteuitos }\end{array}$ & 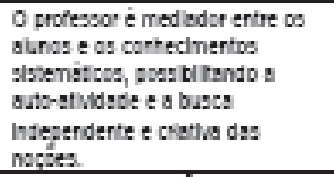 & 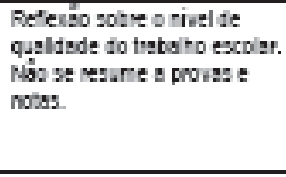 & $\begin{array}{l}\text { Parte da snibe critcs das } \\
\text { realledes soctals. }\end{array}$ \\
\hline $\begin{array}{l}\text { Dez-Eovdenave, } \\
\text { Perelrgla }\end{array}$ & Esquena do Arco & 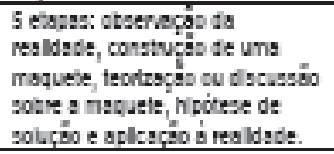 & $\begin{array}{l}\text { Feio desenserho do alurg, } \\
\text { poven de oficli mensureçîn } \\
\text { de todse ce cbjetive do } \\
\text { ensiro. }\end{array}$ & 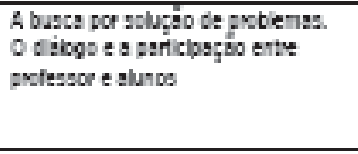 \\
\hline
\end{tabular}

Quadro 2. Abordagens pedagógicas que amparam a análise dos resultados deste estudo. 
era feita de acordo com o conteúdo que ela passou. (A1).

... no final, ela fazia aquela revisão com todo o grupo, do ensinoaprendizado, né? E quando concluía a aula, ela tinha a certeza do que ela tentava transmitir, Pelo menos $70 \%$ ela via que ficava de aprendizado, de um modo geral, do grupo todo, não era $100 \%$, tinha alguns que tinham uma capacidade de captar melhor, mas os outros não conseguiam. (A2).

... lá foi sentado no dia e a professora chegou e disse: 'Fulana, você vai ficar ... eu acho melhor, dentro do seu projeto, você vai enfocar tal parte dele', para fazer esse artigo, para ser uma forma de avaliação da gente, no que transcorreu, que a gente aprendeu e se a gente realmente conseguia fazer um trabalho modelo de artigo. "Então, cada uma vai fazer ... fulana, você vai trabalhar isso no seu tema." (A3)

... quando alguém começava a querer se aproveitar da bondade do professor, da situação, ela tomava aquela postura de cobrar: 'Porque está faltando? Sua nota vai ser diferenciada.' Isso era passado. (A3).

E realmente foi muito justo, porque quem não faltou, quem tinha lido os textos e fez os trabalhos que eram para ser feitos, teve a sua nota numa boa, mas, agora, diferenciada um dos outros, Isso ai foi. (A3).

Tanto a avaliação era contínua, à medida que a gente lia os textos na aula e discutia em sala de aula, isso era uma parte de avaliação, ... (A3).

... a outra forma de avaliação que foi passado para a gente no $1^{\circ}$ dia de aula, seria a pontualidade e também a questão das faltas. Aquelas pessoas que não faltassem teriam uma nota diferenciada daqueles que tivessem faltas. Tanto a questão da falta quanto a questão da pontualidade foi uma coisa assim, bem levada ao pé da letra. (A3). Tanto a participação em sala de aula, era outro fator de avaliação, a participação, a pontualidade e a questão da regularidade, assiduidade, que não faltasse, isso foi um dos pontos. (A3).

... foi estabelecido, na primeira aula, qual era a forma que nós alunos gostaríamos de ser avaliados, qual era a forma que não iria prejudicar ninguém, então aí surgiram: 'Vai ser prova?' 'O que vocês acham melhor?'A gente decidiu pelo seminário, a entrega de um trabalho com um tema que a gente tivesse, que nós tivéssemos a identificação com a temática, então, cada um puxou com um tema que iria ter uma contribuição na sua dissertação, entendeu? (A4).

Constatou-se a existência da contradição na Prática Educativa dos docentes do Programa de Pós-Graduação em Enfermagem do Centro de Ciências da Saúde da Universidade Federal da Paraíba, e, os futuros formadores de força de trabalho em enfermagem poderão reproduzir essa prática.

\section{CONSIDERAÇÕES FINAIS}

A opção por Práticas Educativas que privilegiam a transmissão de conhecimentos, característica das Abordagens não Emancipatórias, que subordinam as atividades de ensino e de avaliação à instrução, precisam ser repensadas, tendo em vista, entre outros fatores, 0 atendimento das exigências da sociedade para com a Universidade, cuja função é formar profissionais conscientes, analíticos e, sobretudo, críticos da sociedade, com competência para julgar e decidir o que fazer, diante das mais diversas situações.

Considerando-se os atuais requerimentos das políticas de educação e de saúde, urge a superação das contradições advindas do confronto entre, a opção por práticas educativas Emancipatórias e não Emancipatórias, como meio para o atendimento das políticas de inclusão social, cada vez mais acentuadas com a redefinição das prioridades de atenção à saúde e a conseqüente necessidade de um novo perfil profissional, longe de ser alcançado pelo paradigma tradicional de formação.

Perrenoud ${ }^{(15)}$ afirma que a Universidade não pode formar profissionais reflexivos, só pelo fato de realizarem pesquisas, sendo, também, necessária a utilização de alguns dispositivos, como análise de práticas, estudos de caso, vídeo-formação, escrita clínica, técnica de autoobservação e de esclarecimento e treinamento para o trabalho.

Para se formar profissionais reflexivos, é necessário que esse objetivo esteja no centro do plano de formação e integrado às demais competências e habilidades profissionais.

Não será possível atingir uma prática reflexiva, como denomina Perrenoud ${ }^{(15)}$, se os formadores persistirem na utilização de abordagens não emancipatórias, que valorizam os conhecimentos desarticulados de um contexto social.

A Universidade parece, a priori, o lugar privilegiado para um olhar crítico sobre a sociedade e sobre a Prática Educativa adotada no PPGEnf do CCS/UFPB, porém, ainda assim, algumas nuanças são evidentes, como a imaginária "torre de marfim"(16), ao redor da Universidade, incluindo aqui o programa de formação de formadores, resguardados dos murmúrios do mundo, para que cada um se consagre à busca serena do saber, onde não se esperar que os discentes sejam estimulados para a participação crítica.

É necessária a presença de professores engajados na crítica radical da sociedade, sem se sentirem responsáveis pelas políticas e práticas sociais, encarregados de identificar e denunciar as incoerências, os comprometimentos, a ineficácia ou as falsas aparências.

Assim, as abordagens Emancipatórias mostram um caminho que leva à superação das contradições, contribuindo para a formação de força de trabalho com competência técnica, política e social.

\section{REFERÊNCIAS}

1. Valente SMP. Do currículo às Diretrizes Curriculares. Olho Mágico, 1999; 5(20).

2. Pinheiros VE, Rodrigues ARF. O processo ensino/aprendizagem na enfermagem. Rev Mineira Enferm 1999; 5(9/10): 62-79.

3. Egry EY. Saúde Coletiva: construindo um novo método em enfermagem. São Paulo (SP): Ícone; 1996.

4. Fiorin JL. Elementos de Análise do Discurso. São Paulo (SP): Contexto - EDUSP; 1999

5. Mizukami MGN. Ensino: as abordagens do processo. São Paulo (SP): EPU; 1986.

6. Freire P. Educação e mudança. $5^{\mathrm{a}}$ ed. São Paulo (SP): Paz e Terra; 1982.
7. Saviani D. Pedagogia histórico-crítica: primeiras aproximações. $5^{a}$ ed. São Paulo (SP): Autores Associados; 1995.

8. Saviani D. Escola e democracia: teorias da educação, curva da vara, onze teses sobre a educação e política. $24^{2}$ ed. São Paulo (SP): Cortez; 1991.

9. Saviani D. Educação: do senso comum à consciência filosófica. São Paulo (SP): Cortez; 1986.

10. Libaneo JC. Adeus professor, adeus professora? Novas exigências educacionais e profissão docente. $7^{\mathrm{a}}$ ed. São Paulo (SP): Cortez; 2003

11. Libaneo JC. Didática. São Paulo (SP): Cortez; 1992.

12. Libaneo JC. Os conteúdos escolares e sua dimensão crítico- 
Formação de formadores: a prática educativa de um programa de pós-graduação em enfermagem

social. Rev Ande 1986; 11.

13. Diaz-Bordenave JD, Pereira AM, Estratégias de ensinoaprendizagem. 20a ed. Rio de Janeiro (RJ): Vozes; 1999.

14. Ferreira $\mathrm{ABH}$. Dicionário de Língua Portuguesa. Rio de Janeiro (RJ): Nova Fronteira; 2001.
15. Perrenoud P. Formar professores em contextos sociais em mudança: prática reflexiva e participação crítica. Rev Bras Educação 1999; 12: 5-21.

16. Huberman $\mathrm{M}$, Thurler MG. De la recherche à la pratique. Berna (SWT): Lang; 1991. 